\title{
Design and Calculation of a Concrete Mixer (100 kg)
}

\author{
Min Min Shwe Sin \\ Department of Mechanical Engineering \\ Technological University (Taunggyi), \\ Southern Shan State, Myanmar
}

\begin{abstract}
In this paper describe the design and calculation of concrete mixer for weight $350 \mathrm{~kg}$ approximately. A concrete mixer machine is a device that homogeneously combines cement, aggregate such as sand or gravel, and water to form concrete.

Concrete is an important component required for construction of houses and roads. However, most operation of mixing concrete in Myanmar is done manually as a result of lack of insufficient machinery and high importation cost.

In this machine, I used the RPM drum of $25 \mathrm{rpm}$, shaft diameter of $40 \mathrm{~mm}$, shaft length of $292 \mathrm{~mm}$ and electric motor power of $3 \mathrm{HP}$. Design consideration of this paper is to calculate Mixing Force, Mixing Value, belt tension and required power by mixer. The result obtained show the Mixing force of $1471.5 \mathrm{~N}$, mixing volume of $0.348 \mathrm{~m}^{3}$ and required power by mixture of 2.43 hp.
\end{abstract}

Keywords- Mixer, Concrete.

\section{INTRODUCTION}

The construction and building industries are expanding on a daily basis as a result of increase in human population and continually demand for shelter. A typical concrete machine mixer uses a revolving drum to mix the components. The compressive strength of concrete depends on the aggregate grading, aggregate/cement ratio as well as the water/cement ratio. The freshly mixed concrete should be workable to be properly placed and the hardened concrete needs to be durable and attain a specific compressive strength.

Concrete is a structural material widely used in the construction industry. It consists essentially of cement, fine aggregate (sand) and coarse aggregate (natural gravels or chippings). These constituent materials proportioned are properly mixed together with water to form the concrete.

The cement serves as the binder to the aggregates while the aggregates serve as the filler materials that give strength to concrete. Concrete has the unique distinction of being the only construction material manufactured on the site, whereas other materials are merely shaped to use at the work site. The amount of concrete used worldwide, ton for ton, is twice that of steel, wood, plastics, and aluminum combined. Concrete's used in the modern world is exceeded only by that of naturally occurring water.

\section{MAIN PARTS OF CONCRETE MIXER}

\section{Drum}

Drum is the mixing chamber. It will rotate in a direction to mix the cement , water and aggregates and in the opposite direction to discharge the concrete mixtures.

2. Blades

Blades are installed inside of the drum and special designed to mix the cement very well.

3. Shaft and Bearing
Shaft and bearing are important in concrete mixers to rotate the drum.

4. Motor

Motor produced the required power to operate the shaft.

5. V-belt

The $\mathrm{V}$ - belt acts as a transmission belt connecting the pulleys; it transmits the power from the motor to the shaft.

6. Pulleys

A pulley is a wheel on a shaft that is designed to support movement and transfer of power between the shaft and belt.

\section{III.WORKING PRINCIPLES OF CONCRETE MIXER}

A typical concrete mixer uses a small revolving drum to mix the components. For smaller jobs the concrete made at the construction site has no time lost in transport, giving the worker sample time to use the concrete before it hardens. Portable concrete mixers may be powered by engines, although it is more common that they are powered by electric motors using standard mains current. Cement, sand and other aggregates are directly added to the mixing drum manually.

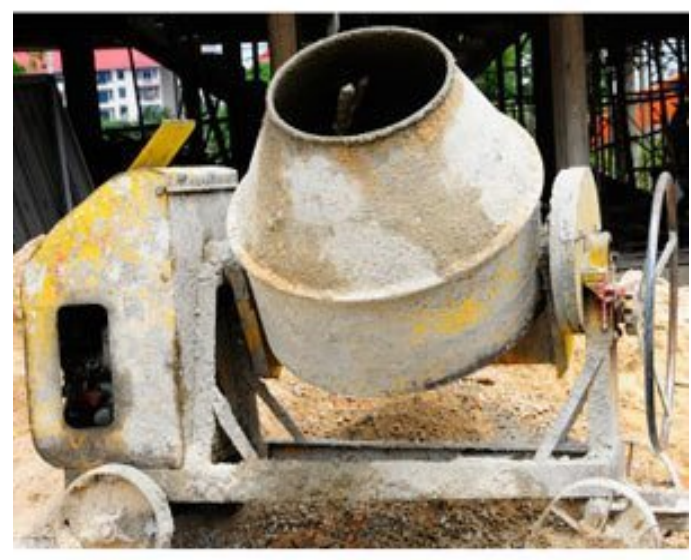

Fig 1. Typical Concrete Mixer

\section{TYPES OF CONCRETE MIXER}

There are two main types of concrete mixers are batch concrete mixers and continuous mixers.

Both types of concrete mixers have their use in different kinds of projects and they serve their purpose well. Concrete mixers are vital part of concrete batching, one cannot overlook their importance. 


\section{Batch Concrete Mixer}

Batch mixers are widely used machines for concrete mixing. Concrete mix obtained by this mixer is collected batch by batch and time by time. So, it is called as batch mixer.

In general, batch concrete mixers are two types;

a. Drum type concrete mixers

b. Pan type concrete mixers

\subsection{Drum Type Concrete Mixers}

This is also called as free fall mixer or gratify mixer. In this type of mixer, concrete is mixed by lifting the ingredients with the help of fixed blades insides a rotating drum and then dropping the material by overcoming the friction between the mixture and the blades. The drum of the mixer can be filled and emptied by changing its directions of rotation, opening it or tipping it up. Rotation speed must carefully follow machinespecific instructions and should not be too fast so that the free fall of the mixture is not interrupted by the centrifugal force.

The drum mixer suits concretes that are not too stiff; usually with a slump up to $50 \mathrm{~mm}$ is commonly used in construction sites. Truck mixers also use free fall mixing. Since the ingredients in a free fall mixer fall from height, there is some attrition of aggregates.

This type of mixers is used for producing large volumes of concrete. These mixers are noted for having high production speeds, low maintenance and ideal for slump concrete.

Drum mixer is available in the following three forms;
a. Tilting drum mixers
b. Non-tilting drum mixers
c. Reversing drum mixers

\subsubsection{Tilting Drum Mixers}

Tilting mixers are usually trailer-mounted or otherwise portable, small to mid-size mixers, used either as main concrete mixing equipment on small sites or as ancillary equipment on sites served by concrete plant. The drum has two axes: one around which the drum rotates and another that serves to change from loading and mixing position (drum opening up) to discharging position (drum opening down). This position change is done manually by a dump wheel (or handle, in the smaller mixers), while drum rotation is electric, gasoline, or diesel powered. Drums are traditionally made of steel, but polyethylene drums for easier cleaning are now offered. Most mixers are of the side-dump type, but end-dump mixers are also manufactured. Material is generally loaded manually, directly into the drum. There are larger-size self-loading units equipped with a tilting hopper. After being filled manually at ground level, the hopper is tilted up mechanically and dumps the material into the drum. A built-in mechanical drag shovel to facilitate aggregate loading into the hopper is optional in some models.

The drum is conical or bowl shaped with internal vanes and the discharge is rapid and unsegregated so that these mixers are suitable for mixes of low workability and for those containing larger size aggregate. The drum axis usually stays at an angle of 15 degree from horizontal during mixing.

Tilt mixer offers consistent mixing with lower operating and maintenance cost. Tilting drum is the most common type of drum mixers for small batches. Tilting mixers can handle larger size aggregates more easily and will discharge mixed concrete rapidly than a non-tilting mixer.

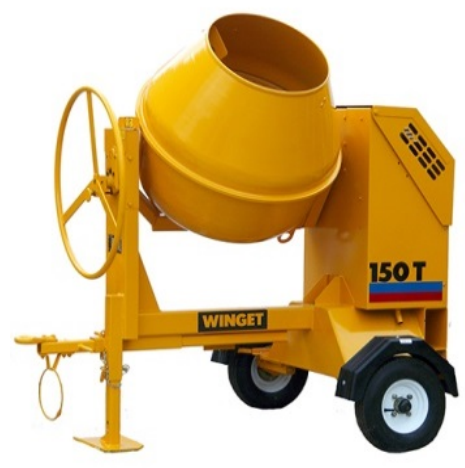

Figure 2. Tilting Mixer

\subsubsection{Non-Tilting Drum Mixer}

A non-tilting drum mixer is one in which the axis of the mixer is always horizontal, and discharge takes place by inserting a chute into the drum or by reversing the direction of rotation of drum. Because of slow rate of discharge, some segregation may occur.

There are two openings, one at each end of the drum: one for feeding the ingredients, the other for discharging the mixture. Blades inside the drum mixes the components to homogenize them into concrete mixers discharge the concrete through a chute, which is placed on an inclined plane.

Needless to say, the discharge time of this concrete mixer is slow. So, non-tilting concrete mixer has its use for smaller projects only. Moreover, this type of concrete mixer is more suitable for mixing smaller size aggregates, because the larger sizes segregate easily. It's mixing capability is also not that much efficient.

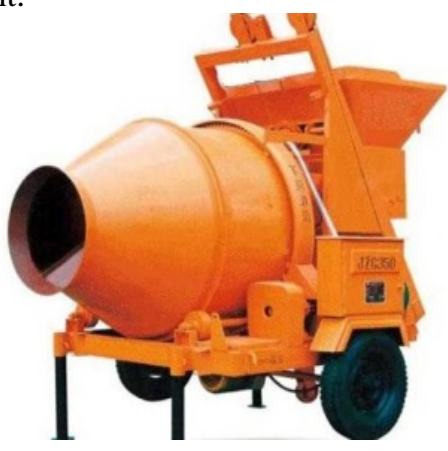

Figure 3. Non-tilting Mixer

\subsubsection{Reversing Drum Mixer}

The reversible drum mixer is similar to the non-tilting mixer except that the same opening is used to add the constituents and to discharge the aggregate. The drum on a reversible mixer has one horizontal axis around which it rotates. In mixing position, the drum rotates in one direction; the blades mix by lifting and dropping the materials during each rotation. Once the materials are sufficiently mixed thee rotation of the drum is reversed and the blade arrangement pushes the concrete through to the discharge end of the mixer.

Commonly self-loading, reversible mixers are mid-size to large-size units mounted on a two-or four-wheeled trailer for transportation between sites. The mixer is equipped with a 
tilting hopper similar to that occasionally found on a tilting mixer, or with a hoist-like hopper that moves up and down on a short inclined set of rails and that dumps the ingredients through a bottom opening into the drum. A built-in mechanical skip to facilitate aggregate loading into the hopper is optional on many models.

Most models of this mixer type are equipped with a water tank and meter, and optionally (the larger models) with a builtin aggregates batcher.

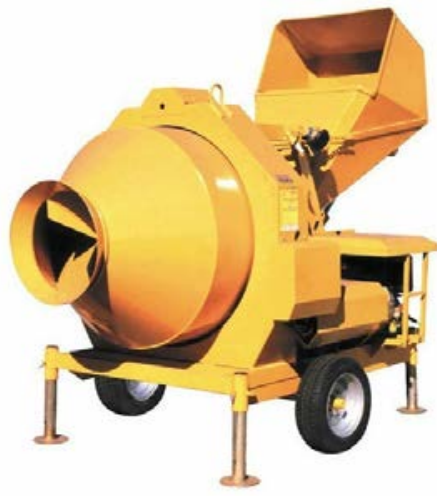

Figure 4. Reversing Mixer

\subsection{Pan Type Concrete Mixers}

Pan type mixers consists a circular pan in which concrete is mixed. The mixing is done by blades which are arranged in star shape inside the pan.

There are two types of pan mixers are available. In one case, the circular pan is constant and only star blades rotate about vertical axis of pan. In the other case, circular pan rotates while the blades are at static position.

But in both cases, the mixing is efficient and concrete mixture is collected through central hole provided in the pan. The rotating star blades contain special blades called scrapper blades which will make concrete not to stick to the pan.

The blades can also be adjusted in height there is no room for concrete to store in the pan. We can say among the all types of batch mixers pan type mixer are more efficient.

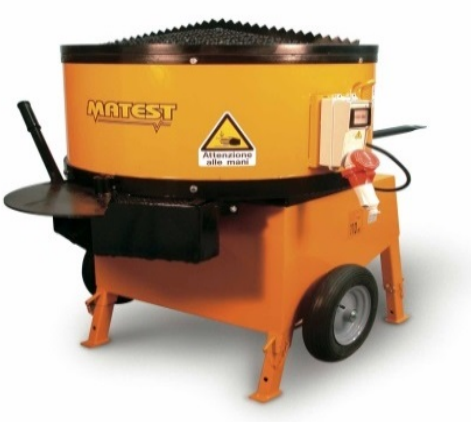

Figure 5. Pan Type Concrete Mixer

\section{Continuous Concrete Mixers}

Continuous concrete mixers produce concrete in continuous manner. So, continuous concrete mixer continues its operation until required amount of concrete is manufactured. Loading of raw materials, mixing and homogenizing of these materials and discharge, all occur in one go without any breaks.

These mixers have their use in very large scale projects like construction of skyscrapers, dams, bridges, etc.

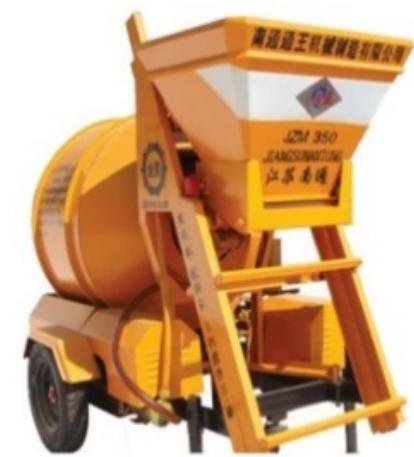

Figure 6. Continuous Concrete Mixer

\section{SPECIAL CONCRETE TRANSPORT TRUCKS (TRANSIT MIXERS)}

Transit mixer is a piece of equipment that is used for transporting concrete or ready mix material from a concrete batching plant directly to the site. They can be charged with dry materials and water, with the mixing occurring during transport. They can also be loaded from a central mix plant with this process the material has already been mixed prior to loading.

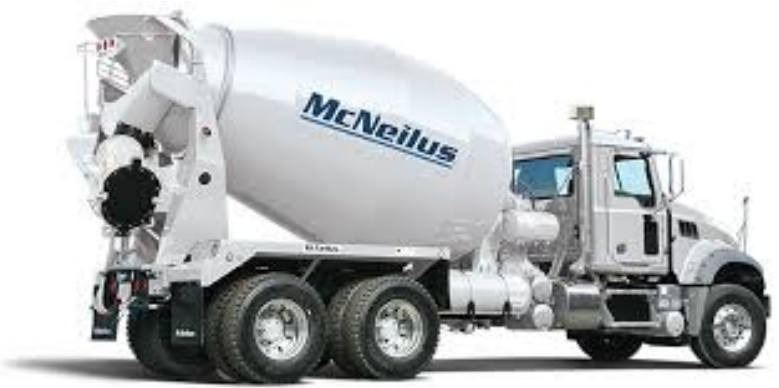

Figure 7. Special Concrete Mixer Truck

\section{METHOD OF CONCRETE MIXING}

In describing the mixing process, the mixer hardware is only one of several components. The mixing process also includes the loading method, the discharge method, the mixing time and the mixing energy.

The loading method includes the order of loading the constituents into the mixer and also duration of the loading period. The duration of loading period depends on how long the constituents are mixed dry before the addition of water and how fast the constituents are loaded. The loading period is extended from the time when the first constituent is introduced into the mixer. The loading period is important because some of the concrete properties will depend on the order in which the constituents are introduced in the mixer. Most operator rely experience and trial and error to determine the loading order of their mixer.

Very often, the mixing time is defined as the time elapsed between the loadings of the first constituents to the discharge of the concrete. In any cases, it is important that the mixing process be described fully for each batch of concrete.

The discharge from the mixer should be arranged so that increases productivity (fast discharge), and it does not modify 
(slow discharge) the homogeneity of the concrete. For instance, if the discharge involves a sudden change in velocity as in falling along distance onto a rigid surface there could be a separation of the constituents by size or, in other words, segregation.

\section{MIXING EFFICIENCY}

As it pointing out, the variables affecting the mixing method are numerous, not always controlled, and not a reliable indicator of the quality of the concrete produced. There is a need for a methodology to determine the quality of the concrete produces as an intrinsic measure of the efficiency of the mixer. The concept of mixer efficiency is used to qualify how well a mixer can produce a uniform concrete from its constituents. Therefore in evaluating mixer efficiency, properties such as segregation and aggregate grading throughout the mixture should be monitored.

\section{Output Rate as an Indicator of Efficiency}

Another indicator of the efficiency of specified mixer is the output rate. The output rate is the amount of concrete produced per a time interval. The output rate is not the measure of the homogeneity of the concrete produce. The output rate depends on the time needed to load the mixer, the mixing time, the discharge time and the cleaning time, if it is a batch mixer. Of course, for reasons of economics, the output rate should be high. However, it should be understood that it is dangerous to base the efficiency of a mixer solely on the output rate because there is no consideration of the quality of the concrete produced.

\section{Mixing Energy}

The mixing en during the whole mixing cycle. For reasons of economics, the mixing energy should be kept low but the quality of the concrete should be considered first.

The power consumption is often used to estimate the workability of the concrete. The theory behind this usage is based on the principles of operation of a rheometer. A rheometer is an instrument that measure the stress generated by the material tested while applying a strain. In this case strain is the constant speed of the blades and the stress is measured by the energy consumption.

Therefore, the mixing energy is very useful tool to determine the variation in the workability of the concrete being produced.

\section{Wear and Tear, Cleanness}

In determining mixer efficiency, the main focus has been determining the homogeneity and the quality of the concrete produced. It was assumed that the mixer was operating as designed by its manufacturer. But long usage of a mixer leads to wear of the blades and/or scraper, or the build-up of materials (hardened motor or cement paste) on the blades, the container, and/or the scraper. Wear and build -up will change the geometry of the mixer and therefore the flow pattern of the concrete, and may lead to changes in the concrete mixer should be thoroughly cleaned at the end of each day of operation and the blades and/or scraper changed on a regular schedule.

\section{METHODOLOGIES}

Specification data for design calculation of a concrete mixture for $100 \mathrm{~kg}$ describe in table 1.

Table 1. Specification Data

\begin{tabular}{|l|l|l|l|l|}
\hline No & Description & Symbols & Value & Units \\
\hline 1 & Upper radius of drum & $\mathrm{r}_{\text {upper }}$ & 250 & $\mathrm{~mm}$ \\
\hline 2 & Middle radius of drum & $\mathrm{r}_{\text {middle }}$ & 450 & $\mathrm{~mm}$ \\
\hline 3 & Bottom radius of drum & $\mathrm{r}_{\text {bottom }}$ & 300 & $\mathrm{~mm}$ \\
\hline 4 & Acceleration due to gravity & $\mathrm{g}$ & 9.8117 & $\mathrm{~m} / \mathrm{s}$ \\
\hline 5 & Overall height of drum & $\mathrm{h}$ & 1000 & $\mathrm{~mm}$ \\
\hline 6 & Mass of drum & $\mathrm{m}_{\text {drum }}$ & 50 & $\mathrm{Kg}$ \\
\hline 7 & Mass of concrete mixture & $\mathrm{m}_{\text {concrete }}$ & 100 & $\mathrm{Kg}$ \\
\hline 8 & Motor RPM & & 950 & $\mathrm{rpm}$ \\
\hline 9 & Diameter of driven pulley & $\mathrm{D}_{1}$ & 150 & $\mathrm{~mm}$ \\
\hline 10 & Diameter of driver pulley & $\mathrm{D}_{2}$ & 300 & $\mathrm{~mm}$ \\
\hline 11 & Belt width & $\mathrm{b}$ & 30 & $\mathrm{~mm}$ \\
\hline 12 & Belt thickness & $\mathrm{t}$ & 8 & $\mathrm{~mm}$ \\
\hline 13 & Rubber belt density & $\delta$ & 1250 & $\mathrm{Kg} / \mathrm{m}^{3}$ \\
\hline 14 & Allow stress for rubber belt & $\mathrm{S}_{1}$ & 1 to 17 & $\mathrm{MP}_{\mathrm{a}}$ \\
\hline
\end{tabular}

Calculation Procedure of Concrete Mixer involves the following steps.

1. Mixing force of the concrete mixer

$$
\mathrm{F}=\mathrm{M}_{\mathrm{T}} \times \mathrm{g}
$$

2. Determination of mixing volume

The volume of mixing chamber can be calculated by the following equation;

$$
\mathrm{V}=\pi_{\text {mean }}^{2} \mathrm{~h}
$$

3. Mean radius of drum

$$
\mathrm{r}_{\text {mean }}=\frac{\mathrm{r}_{\text {upper }}+\mathrm{r}_{\text {middle }}+\mathrm{r}_{\text {buttom }}}{3}
$$

4. Speed ratio for belt drive

The speed ratio for belt drive is the ratio between the velocity of the diver and the driven pulley. It may be express as;

$$
\frac{\mathrm{N}_{2}}{\mathrm{~N}_{1}}=\frac{\mathrm{D}_{1}}{\mathrm{D}_{2}}
$$

\section{Center Distance between Two pulleys}

$$
\mathrm{C}=2 \mathrm{D}_{1}+\mathrm{D}_{2}
$$

\section{Determination for belt length of open type}

To calculate the V-belt length required to connect two pulleys for mechanical power transmission. The belt length can be obtained by the following equation;

$$
L=2 C+\frac{\pi}{2}\left(D_{1}+D_{2}\right)+\frac{\left(D_{1}+D_{2}\right)^{2}}{4 C}
$$

7. Belt Contact Angle between belt and Pulley

$$
\sin \beta=\frac{D_{2}-D_{1}}{2 C}
$$




\section{Determination of belt tension}

Belt tension is a critical step when installing a belt. V- belt operate on friction; the friction is multiplied by the mechanical advantage of the wedging principle. Correct V-belt tensioning is the single most important factor necessary for long, satisfactory operation.

$$
\begin{aligned}
& \mathrm{V}=\frac{\pi \mathrm{DN}}{60} \\
& \frac{\mathrm{T}_{1}-\mathrm{mv}^{2}}{\mathrm{~T}_{2}-\mathrm{mv}^{2}}=\mathrm{e}^{\mathrm{fa}}
\end{aligned}
$$

9. Determination of lap angle

$$
\alpha=180-2 \sin ^{-1}\left(\frac{\mathrm{D}_{2}-\mathrm{D}_{1}}{2 \mathrm{C}}\right)
$$

10. Belt tension

$$
\mathrm{T}_{1}=\mathrm{S}_{1} \times \mathrm{b} \times \mathrm{t}
$$

11. Belt power

$$
\mathrm{P}=\left(\mathrm{T}_{1}-\mathrm{T}_{2}\right) \mathrm{V}
$$

Table 2. Result Data

\begin{tabular}{|l|l|l|l|l|}
\hline No & Description & Symbols & Value & Units \\
\hline 1 & Mixing force & $\mathrm{F}$ & 1471.5 & $\mathrm{~N}$ \\
\hline 2 & Means radius of drum & $\mathrm{r}_{\text {mean }}$ & 0.333 & $\mathrm{~m}$ \\
\hline 3 & Mixing Volume & $\mathrm{V}$ & 0.348 & $\mathrm{~m}^{3}$ \\
\hline 4 & Speed of driver & $\mathrm{N}_{1}$ & $\begin{array}{l}950(\text { motor } \\
\text { power) }\end{array}$ & $\mathrm{rpm}$ \\
\hline 5 & Speed of the driven & $\mathrm{N}_{2}$ & 475 & $\mathrm{rpm}$ \\
\hline 6 & $\begin{array}{l}\text { Center distance between } \\
\text { two pulleys }\end{array}$ & $\mathrm{C}$ & 0.6 & $\mathrm{~m}$ \\
\hline 7 & Belt length & $\mathrm{L}$ & 1.9162 & $\mathrm{~m}$ \\
\hline 8 & Belt contact angle & $\beta$ & 7.181 & $\mathrm{rad}$ \\
\hline 9 & Velocity & $\mathrm{v}$ & 7.461 & $\mathrm{~ms}{ }^{-1}$ \\
\hline 10 & Warp angle & $\alpha_{1}$ & 2.89 & $\mathrm{rad}$ \\
\hline 11 & Warp angle & $\alpha_{2}$ & 3.39 & $\mathrm{rad}$ \\
\hline 12 & $\begin{array}{l}\text { Tension in the tight side } \\
\text { of the belt }\end{array}$ & $\mathrm{T}_{1}$ & 408 & $\mathrm{~N}$ \\
\hline 13 & $\begin{array}{l}\text { Tension in the stack side } \\
\text { of the belt }\end{array}$ & $\mathrm{T}_{2}$ & 64.018 & $\mathrm{~N}$ \\
\hline 14 & Belt power & $\mathrm{P}$ & 2.43 & $\mathrm{hp}$ \\
\hline
\end{tabular}

\section{CONCLUSION}

Concrete is used extensively for construction purpose. Considering the usage of concrete, mechanization of the process is required to increase production output.

Furthermore, mixing is a complicated process that is affected by the type of mixer, the loading method, the energy of mixing, and most importantly the material for the blade. In this design, a stainless steel material was selected as a result of strength, corrosion was overcome in this new design.

In my paper, concert mixer, designed for the user should be cheap, easy to maintain and easy to use for mixing. And then local material should be used. According to the design calculation of mixer concrete required mixing force $1500 \mathrm{~N}$ and transmission power required $2.43 \mathrm{hp}$.

\section{ACKNOWLEDGMENT}

The author wishes to mention her heartfelt thanks to our Rector, Dr. San San Yee, Technological University (Taunggyi) , for giving valuable suggestion and wise guidance. The author would like to express all for her teachers and parents who taught her everything from childhood until now and her colleagues for their encouragement, helpful suggestion, true-line guidance, supervision this paper.

\section{NOMENCLATURE}

\begin{tabular}{|l|l|l|l|}
\hline No & Symbols & Description & Unit \\
\hline 1 & $\mathrm{M}_{\mathrm{T}}$ & $\begin{array}{l}\text { Total mass ( mass of concrete t mass of } \\
\text { drum) }\end{array}$ & $\mathrm{kg}$ \\
\hline 2 & $\mathrm{r}_{\text {mean }}$ & mean radius & $\mathrm{mm}$ \\
\hline 3 & $f$ & Coefficient of fraction & \\
\hline
\end{tabular}

\section{REFERENCES}

[1] C.F.Ferrasis, Concrete Mixing Methods and Concrete Mixers; State of the Art,"Journal of Reserarch of the National nstitute of Standards and Technological”.

[2] Design and Fabrication of an Industrial Mixer; Internatinal journal of Pratctices and Technologies ISSN 1583-1078 issue 20, Jauary , June 2012, by Thompsonn Aguheve.

[3] Concrete Mixer ; By Turley, Jr, Civil Engineering, B.S 1913, University of Illinois Library.

[4] https://en.wikipedia.org/w/index.php? Title = concrete. Mixer and dcild $=848603025$. 